\title{
The comparative study of the static friction coefficient between chain link and different types of polyamides
}

\author{
Radu Papuc ${ }^{1, *}$, Mihai-Tiberiu Lates $^{2}$ \\ ${ }^{1}$ Transilvania University of Brasov, Romania \\ ${ }^{2}$ Transilvania University of Brasov, Romania
}

\begin{abstract}
This paper has as scope the comparative analysis of the experimental study of the static friction coefficients between the chain links and two guide types (segments cut from the tensioning guide of the transmission chain used in combustion engines). Basically, this study will be performed for the contact between steel and different types of polyamides PA46 and PA66, using two tribometers. In the first stage there will be presented the tribometers, devices and work methods followed by the tests results. The next stage presents with the help of finite element analysis the contact pressure variation and displacements distribution. At the end of the paper there are presented the conclusions of the tests performed on the two tribometers.
\end{abstract}

\section{Introduction}

It is known the fact that, if two bodies are put in contact, so that one exerts pressure on the other, results a tangent force on each of the bodies contact surface, called sliding friction force. It is also known, that this tangent force represents the action of a body onto the other body being equal and with opposite direction on each of the two contact surfaces G. W. Stachowiak, A. W. Batchelor [1].

Knowing the parameters of friction is an essential issue in tribological research, because friction always appears when there is a relative rotation between surfaces found in contact.

Friction is produced in the absence of lubricant (dry friction) or in the partial or total presence of the lubricant (limit friction, mixed, elastohydrodynamic, hydrodynamic, hydrostatic etc.) W. Shizhu, H. Ping [2].

The friction phenomenon is characterized by a multitude of parameters. Amongst them, one of the most important (if not the most important) is the friction coefficient F. C. Chiu, G. F. Kao [3].

The friction coefficients are of two types: static friction coefficient $\mu_{s}$ and kinetics friction coefficients (dynamic) $\mu_{c}$ B. Mouhmid, A. Imad, N. Benseddiq [4]

The static friction coefficients are the coefficients that appear at the limit between stop and movement, so at the start. Knowing the static friction coefficients represent a specific importance, especially in the friction joints where the starts and stops are frequent .

Because of the multiple factors that can interfere in the friction process, the calculation equations for determining the friction coefficients are complex and difficult to resolve. For this reason, it is very important that the friction coefficients are determined through experimental methods, but with a high precision J. Williams [5].

\section{Describing the test and methodology of testing}

For the experimental determination of the static friction coefficients between the chain links and guide segments, there will be used two types of tribometer, prismatic and UMT, presented in figures 1 and 2 .

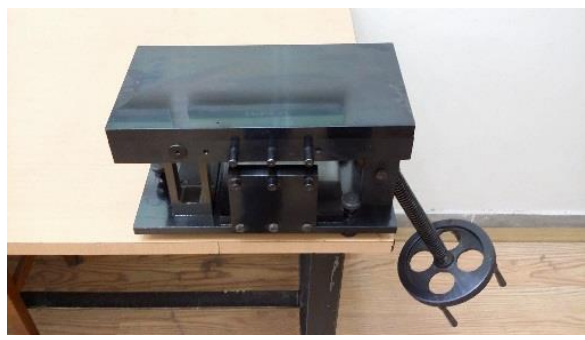

Fig. 1. Prismatic tribometer

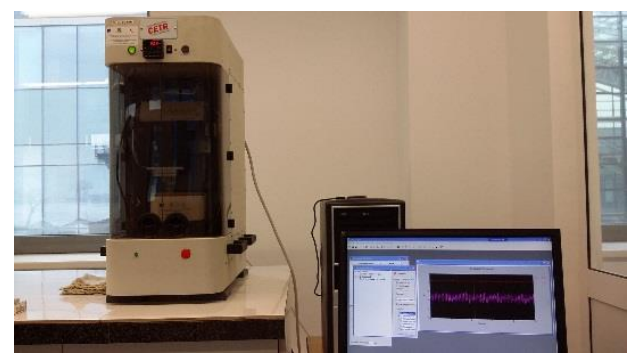

Fig. 2. Tribometer UMT

The prismatic tribometer has a simple functioning principle, being expressed with the relation 1 and detailed in figure 3 :

\footnotetext{
* Corresponding author: radu.papuc@,unitbv.ro
} 
Where $\alpha$ is the tilt angle of the mobile table and $\mu$ is the sliding friction coeffiecient.

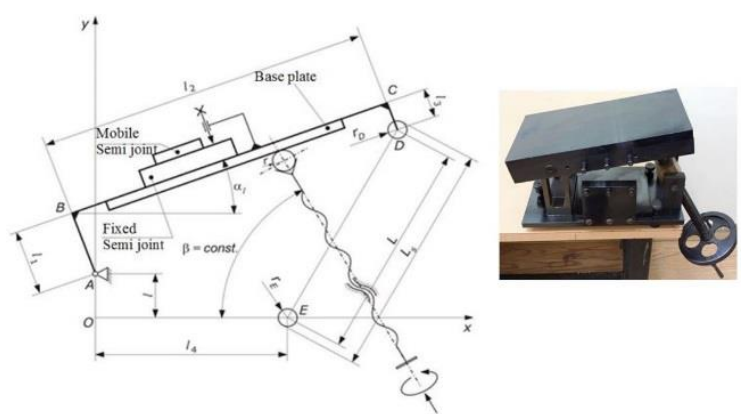

Fig. 3. Functioning principle of the prismatic tribometer

The other tribometer, UMT, works by being controlled through a software installed on a computer. In order to determine the static friction coefficients, on the UMT tribometer there will be connected two modules: reciprocating and rotary. These modules are shown in figures 4 and 5 .

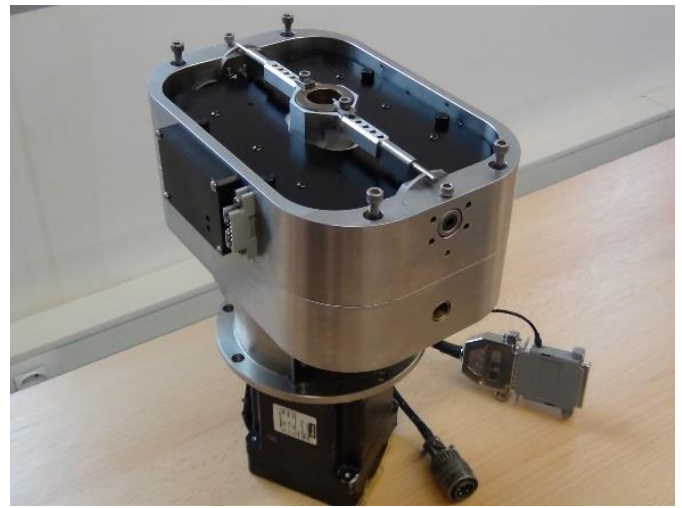

Fig. 4. Reciprocating module

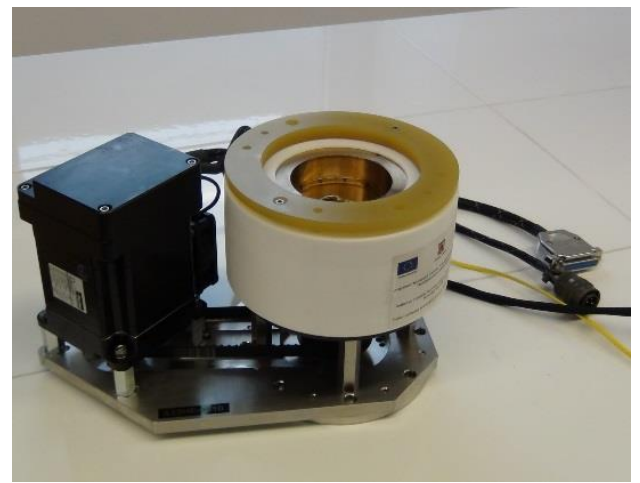

Fig. 5. Rotary module

The reciprocating module, shown in figures 3 and 4, is suitable for performing tests on small samples of different pieces, and the motion is alternative rectilinear. The work frequency of the module is between $0.1-60 \mathrm{~Hz}$, and the maximum load is $\mathrm{F}=1000 \mathrm{~N}$.

Also, the rotary module, presented in the same figure, is suitable for experimental determination in rotational motions. The torque value range $0.001-5000 \mathrm{rpm}$, and the maximum load force is $\mathrm{F}=1000 \mathrm{~N}$.
To evaluate the static friction coefficient between the tooth chain links and guide segments there were designed and built four testing devices C. C. Gavrilă [6]. In figure 6 , there are presented the models used for tdetermining the friction coefficient, in the laboratory conditions from Transilvania University Research Institute. All models were designed with CATIA V5.

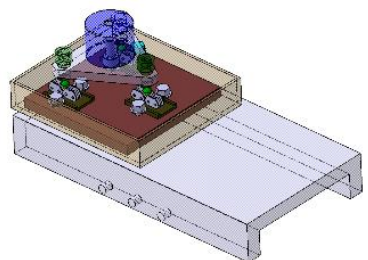

device $\mathrm{A}$

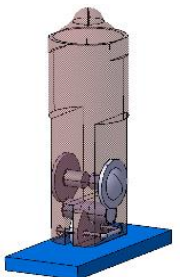

device C

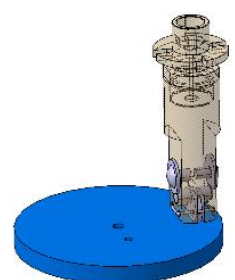

devide $\mathrm{B}$

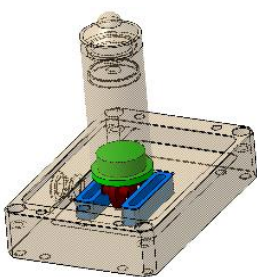

device $\mathrm{D}$
Fig. 6. Device used to determine the static friction coefficients

In the prismatic tribometer there were performed two study cases: case I - determining the static friction coefficient at contact between the tooth chain links and PA46 polyamide guide segments, in lubricated environment; case II - determining the static friction coefficient at contact between the tooth chain links and PA66 polyamide guide segments, in lubricated environment, presented in figure 7 .

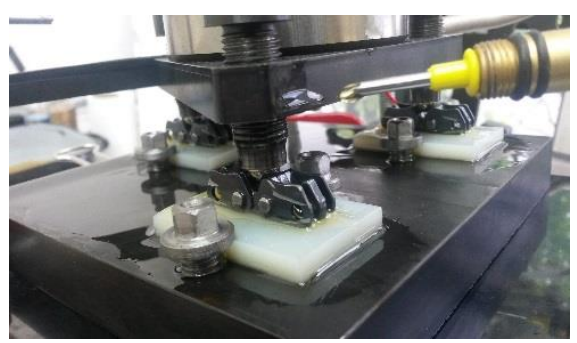

Fig. 7. Prismatic tribometer

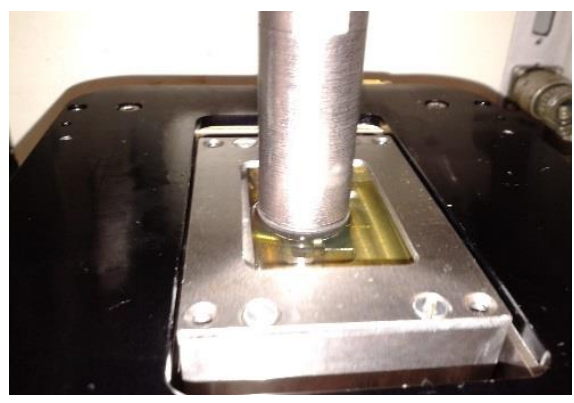

Fig. 8. Reciprocating module

On the other testing tribometer, UMT, there were performed four study cases in order to determine the static friction coefficient at contact between tooth chain links 
and guide segments (made from polyamides, PA46 and PA66). These experimental tests were done on the Reciprocating, presented in figure 8 and Rotary modules. Thus the imposed condition of the tests were normal force $\mathrm{F}=5 \mathrm{~N}$ and lubricant: $15 \mathrm{~W}-30$ engine oil. The results of the experimental tests are presented in figures 9 and 10 .

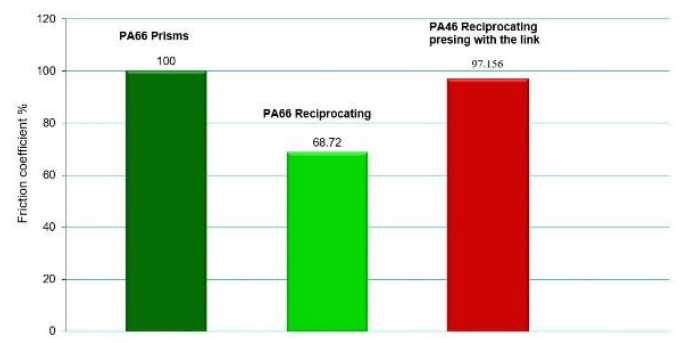

Fig. 9. Comparation prisms and reciprocating

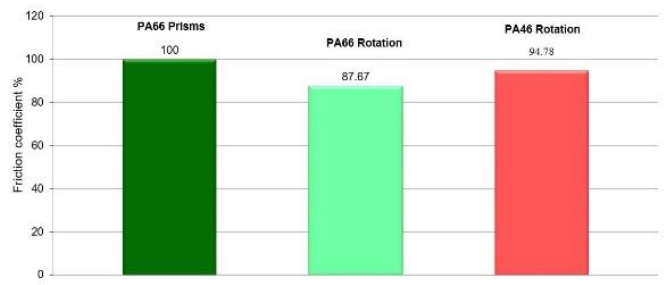

Fig. 10. Comparation prisms and rotary

It has to be mentioned that, in this paper, the values obtained for the reference measures as friction coefficients are presented as relative or percentage values, expressing dependence on parametes for which absolute values are used. This fact was imposed by the confidentiality conditions resulted from framing this research in the contract Chain Drive System Dynamic Friction.

\section{The study of contact pressure}

The finite elements method is a numerical method used at solving partial derivatives equations which model physical systems with an infinite number of freedom degrees. By using finite element analysis these equations are reduced to algebraic equations systems, meaning a discrete system with a finite number of freedom degrees.

In order to have a higher efficiency, in finite element analysis it is used a general structure concept and simpler than regular one. Usually, in finite element analysis by structure (of resistance) it is understood an assemble of bars, plates, layers and volumes (solids).

Finite elements method has applicability in various engineering domains (and not only), where there are found pysical phenomena described by partially derivatives equations. Amongst the main domains there are: structural analysis, fluids, magnetical and electrical analysis J. E. Akin [7].

The numerical evaluation of the previously studied concepts, here the determining the deformation state as well as the contact distribution between the interest elements (guide and bolt). Determining the tensioning state is not taken into consideration because the applied forces are hot big and the physical models are rigid enough so that they can withstand higher loads. For the numerical evaluation of the studied models it was used the ANSYS Workbench software M. T. Lateş, R. Velicu and R. Papuc [8].

The assembly model with finite elements is shown in figure 11 , a and in figure $11, \mathrm{~b}$ is shown a detail on the bolt meshing.

On the elements found in contact there was made a finer meshing, meaning it had more layers of finite elements and nodes in order to have a better convergence of the results and contact from that area. After meshing there were obtained 16234 finite elements and 67696 modes.

For this model there are shown two calculation cases, as follows: case 1: guide material PA46, $\mathrm{F}=5 \mathrm{~N}$ and $\mu=0.28$; case 2: guide material PA66, $F=5 \mathrm{~N}$ and $\mu=0.28$;

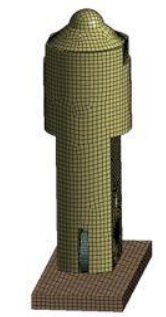

a-general view

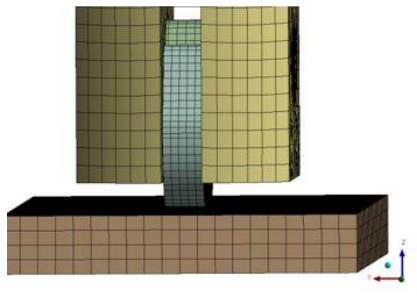

b-bold detailed view
Fig. 11. Finite elements model

The method of applying the force is presented in figure 12 being identical for both analyzed cases.

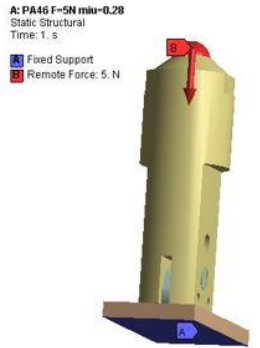

a-the method of applying the force

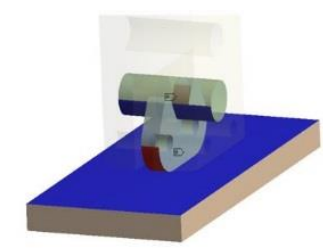

b-defining contacts
Fig. 12. The method of applying the force and defining contacts in ANSYS

For load case 1, of this model, the obtained value of maximum displacement is $0.0005 \mathrm{~mm}$, figure $13 \mathrm{a}$.

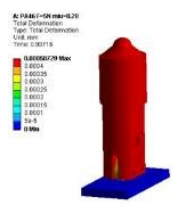

a

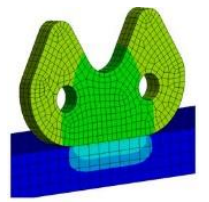

b

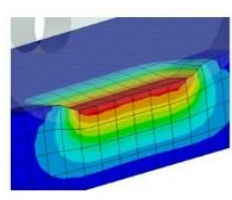

c
Fig. 13. The displacement distribution

If it is made a detailed value on the guide it is observed that the guide is deformed locally and only on the contact zone between the guide and bolt. In figure $13 \mathrm{~b}$, it is shown the guide deformation at a scale $1: 1$, and in figure 
$13 \mathrm{c}$, it is shown the guide deformation at an enlarged scale by 3000 times, only for visualization. The distribution of the contact pressure between guide and bolt, in this case, it is shown in figure 14 and has an uniform distribution with higher values towards the interior of the bolt, the maximum value of the contact pressure being $0.54 \mathrm{MPa}$. The maximum contact pressure between bolt and sprocket is $4.57 \mathrm{MPa}$ being distributes uniformly on the tangent line between the bolt and the sprocket generator.

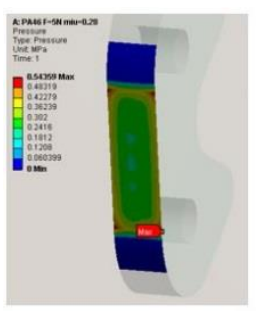

a-the contact pressure between guide and bolt

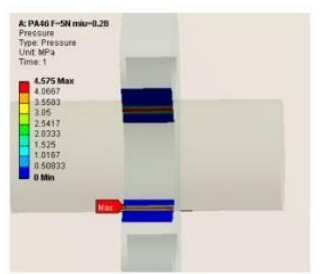

b-the contact pressure between stud and guidee
Fig. 14. The distribution of the contact pressure

For case 2, where the guide material is PA66, the maximum displacement is $0.00046 \mathrm{~mm}$, figure 15 . It is observed that the displacement value is lower than case 1 , where it is applied the same loading force, from where it can be concluded that the PA66 material is more rigid than PA46, the friction coefficient not having any influence in this case.

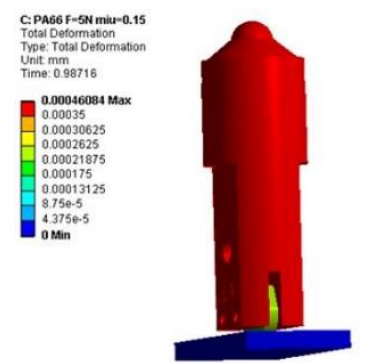

Fig. 15. Displacements distribution

The values of the contact pressures and their distribution on this model are identical with the ones obtained in loading case 1 , but with material PA46. Thus, the maximum value of the contact pressure between guide and bolt is $0.54 \mathrm{MPa}$, and between stud and bolt is 4.57 $\mathrm{MPa}$.

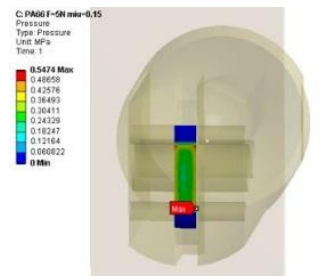

a-pressure distribution between guide and links

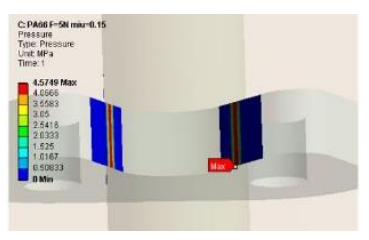

b- pressure distribution between bolt and links
Fig. 16. The distribution of the contact pressure

\section{Conclusion}

Based on the obtained results after the experimental tests and the comparative analysis of the two materials, it was found that PA66 polyamide has better characteristics in terms of friction reduction. These results show that from tribological point of view, the pair of materials analyzed have a specific behaviour different that the general know one characterized by the Stribeck curve.

On the basis of the results obtained after the study, using finite elements analysis it is highlighted that for the contact between the chain links and two guide segments there were obtained small values for the contact pressure due to high mechanical characteristics of the studied polyamide. It must be mentioned that these results are in accordance with the specific literature Van, J. Ruiten, R. Proost, and M. Meuwissen [9]. Because the transmitted force from the application point to the fastening point is done only throught the contacts between components, there were no significat equivalent tensions.

\section{References}

1. G. W. Stachowiak, A. W. Batchelor, Engineering tribology (Ed. Elsevier, 3rd ed., Burlington, 2005).

2. W. Shizhu, H. Ping, Principles of Tribology (Singapore, John Wiley \& Sons Publishing House, 2012).

3. F. C. Chiu, G. F. Kao, Polyamide 46/multi-walled carbon nanotube nanocomposites with enhanced thermal, electrical and mechanical properties in Composites, Part A, nr. 43, 208 - 218, (2012).

4. B. Mouhmid, A. Imad, N. Benseddiq, D. Lecompte, An experimental analysis of fracture mechanics of short glass fibre reinforced polyamide 6.6 (SGFRPA66) in Journal of Composite Science and Technology, nr. 69, 2521 - 2526, (2009).

5. J. Williams, Engineering tribology (Cambridge University Press, USA, 2011).

6. C. C. Gavrilă, 3D Modeling, FEM analysis and detail design for a testing device with spherical joint (In: Annals of the Oradea University, Fascicle of Management and Technological Engineering, vol. XIII (XXIII), ISSUE 1, pp.39-42, 2014).

7. J. E. Akin, Finite Element Analysis for Undergraduates (Academic Press, Orlando, Florida, USA, 1996).

8. M. T. Lateş, R. Velicu, R. Papuc, Multiscale modelling of chain-guide contact by using tests and FEM. 11th World Congress on Computational Mechanics WCCM XI, Barcelona, Spain, 20-25 July, P.1062-1069, (2014).

9. Van, J. Ruiten, R. Proost, M. Meuwissen, How the choise of the polyamide type in timing chains tensioning systems affects the $\mathrm{CO}_{2}$ emission and fuel economy of internal combustion engines in Presentation at VDI Veetiltrieb un Zylinderkopf November 28th, (2012). 